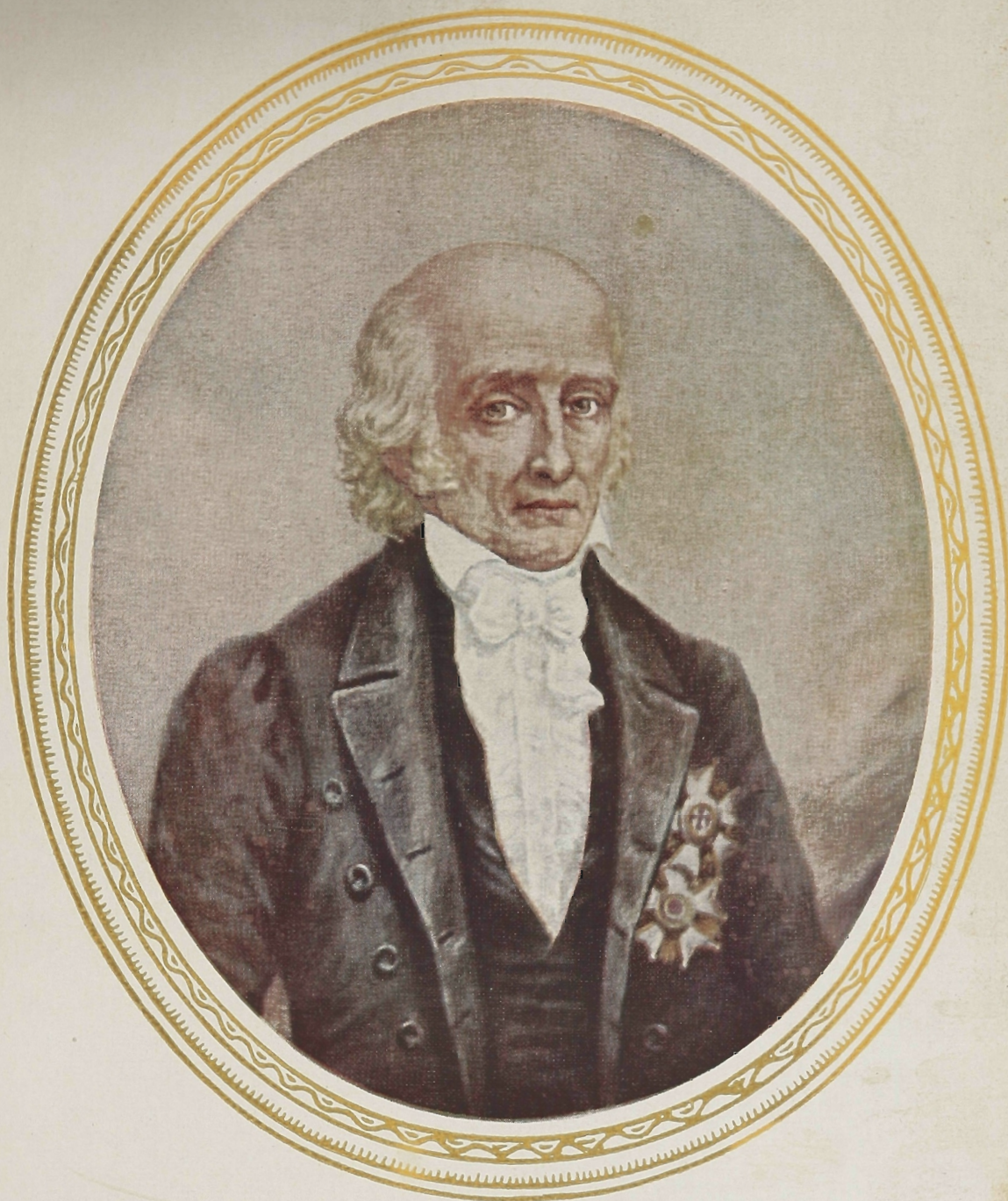

JOSÉ DA SILVA LISBÔA

Visconde de Cayrú

Copia de uma fotografia existente na Biblioteca da Faculdade de Direito da Universidade de S. Paulo 


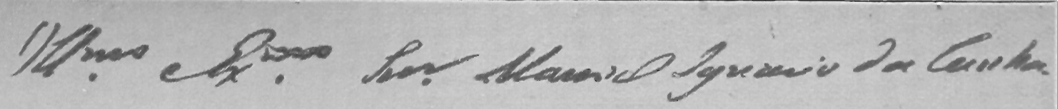
his oe havecis 24 de ctonit er 1824. .15

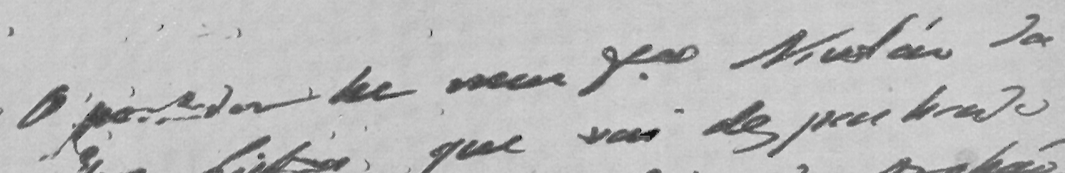

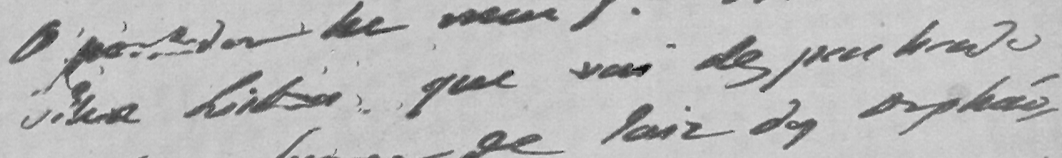

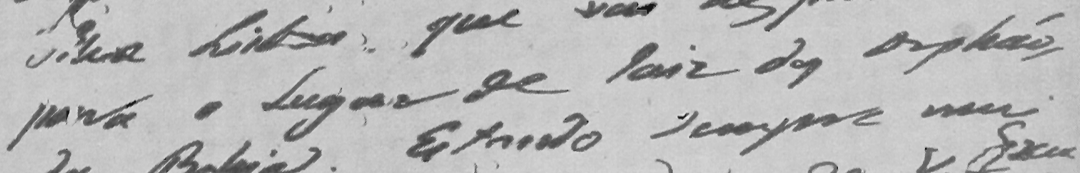

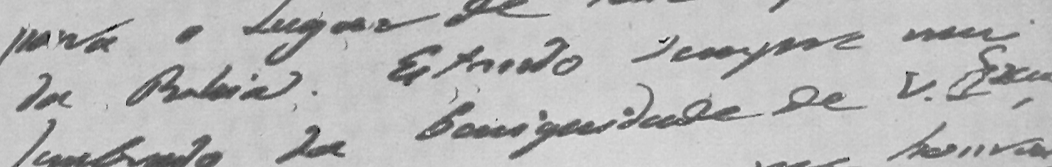

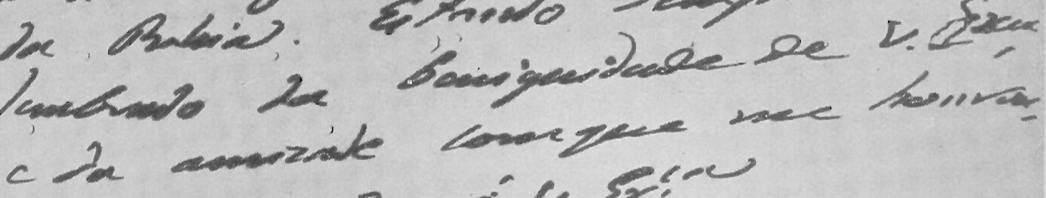

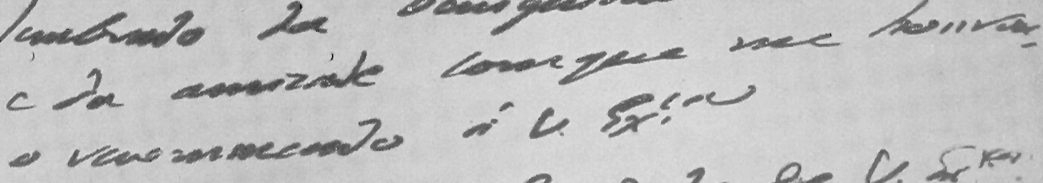

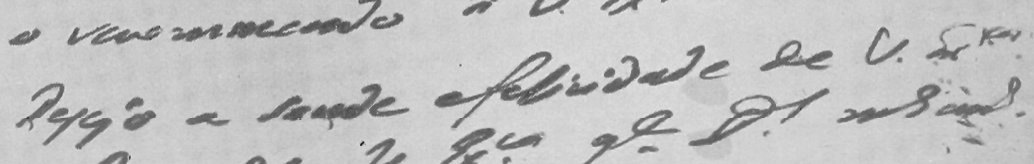

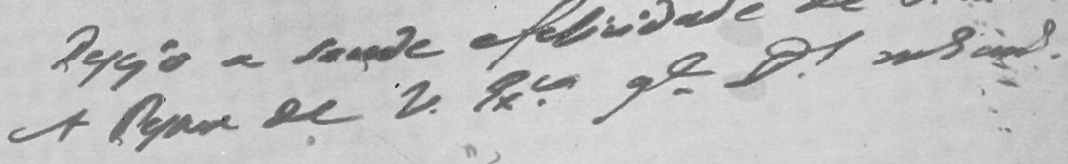

De $4 S_{x}$.

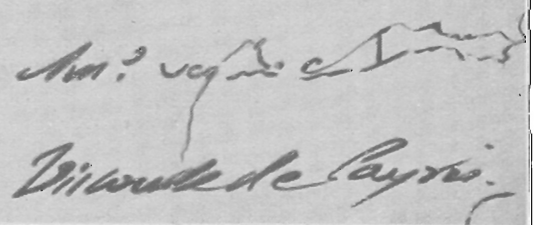




\section{O Visconde de Cayrú}

A Faculdade de Direito da Universidade de São Paulo, publicando o retrato de José da Silva Lisbôa (Visconde de Cayrú) não só quer homenagear um dos mais inspirados elaboradores da Lei de 11 de agosto de 1827, que criou os Cursos Juridicos, mas tambem o patriarcha do Direito Commercial Brasileiro.

No Brasil Colonial, quando não existia ainda uma literatura juridica brasileira, e nos abeberavamos sómente nas obras de Paschoal José de Mello Freire, Manoel de Almeida e Souza e Joaquim José Caetano Pereira e Souza, surgiu o glorioso Visconde de Cayrú, figura tão grande que ainda hoje projecta intensa luz no direito mercantil patrio. Os seus Principios de Direito Mercantil e Leis da Marinha, bem como os Principios de Economia Politica, revelam vastissima erudição para o seu tempo, e constituem marcos miliarios na historia do pensamento juridico brasileiro. Demonstram a alta capacidade intellectual de quem, tornado Ministro de D. João VI, abriu os portos do Brasil ao commercio de todas as Nações amigas, e suggeriu mais tarde ideias avançadas na primeira Assembléia Constituinte.

Ha um conceito do Visconde de Cayrú, em discurso no Senado, que se lhe póde applicar, a elle proprio, com toda a justeza - "Ás vezes um só homem vale mais que mil, para illustrar uma Nação".

Nasceu na Bahia, em 16 de julho de 1756, e falleceu no Rio de Janeiro, em 20 de agosto de 1835. 